\title{
Education Problems and Solutions of Children of Migrant Workers in Heilongjiang
}

\author{
Wei Xu \\ Institute of Educational Theory, Musical Department, Heihe College, Heilongjiang, China
}

Keywords: education of migrant worker's children; demography perspective

\begin{abstract}
This investigation based on data of Heilongjiang Province, focus ones analysis of migrant workers, the migration characteristics and trend of the education of their children from a demographic perspective, reveals the unfavorable factors of present basic education and management system of floating population, based on how to resolve problems in education for the children of migrant workers, and puts forward strategic thinking and suggestions.
\end{abstract}

\section{Introduction}

Based on the education for children of migrant workers to collect relevant information and statistics from the domestic and foreign research results, through a questionnaire survey of Jiading District, Heilongjiang province Yangpu District three schools for children of migrant workers, combined with the relevant functional departments of Education Commission of Heilongjiang Province, Yangpu District Education Bureau, Pudong, Minhang two school children of migrant workers based on the analysis of interview data of the children of migrant workers education at the present stage of big city, according to the characteristics of migration of migrant workers and the future trend of development, education for children of migrant workers at the present stage is the main existing problems are analyzed, and how to solve the education of children of migrant workers put forward the strategic ideas and policy recommendations (Adeline, 2013).

\section{Analysis of Education Problems of Migrant Workers' Children}

\subsection{Provider of education for migrant workers' children}

The main problems facing the two levels of government and schools of the city area as a provider of education for children of migrant workers, city, district two class government is mainly responsible for the education management and financial transfer expenditure duties, accept the migrant workers' children school is mainly responsible for the task of teaching (Baiansy, 2011). Through the field investigation in Shanghai, combined with the public reports and research information in other parts of the country, this paper holds that the education of migrant workers' children is mainly faced with the following problems (Pang, 2012).

\subsection{The relevant statistical system has not yet been established}

The relevant statistical system has not yet been established, and the number of school-age children of migrant workers in the compulsory education stage is unknown, so it is difficult to monitor the enrolment rate and consolidation rate of these students ( $\mathrm{Li}, 2013)$. Because our country has not yet established a registration system of population management, statistical work is still not perfect, the relevant departments can not provide compulsory education for children of migrant workers population data is more accurate, the Department of education as the functional departments, the number of master only their own educational needs of children of migrant workers, and to provide educational opportunities for them. Such institutional framework not only affects the formulation of compulsory education planning for migrant workers' children, but also is difficult to monitor the enrolments rate and consolidation rate of these students (Zhang, 2007). 


\subsection{Student status management is not connected}

The disorderly flow of migrant workers, the school roll management has not yet been networked, increased the difficulty of compulsory education management and education development planning. The migrant workers work and residence is not stable, the children had to learn in order to continue to frequent transfer, and schools for children of migrant workers migrant children, the transfer rates and per capita transfer times are high, liquidity and more schooling. Frequent transfer not only affects the coherence of education, but also puts forward higher requirements for regional education planning management and student status management.

\subsection{The number of floating families is increasing}

The migration of migrant workers and the adjustment of industrial layout to the suburbs, resulting in the regional shortage of compulsory education resources supply contradiction from suburban areas to part of the outer suburbs expansion. At present, China has entered the stage of family development of floating population, and the proportion of floating population's family migration and overall mobility has increased significantly. The results of the family development of floating population lead to a substantial increase in the number of migrant children in the compulsory education stage. In addition, with the spatial adjustment of industrial structure in Shanghai, especially the transfer of industrial parks to the outer suburbs, the migrant workers in Shanghai have also gathered to the suburbs and some suburban areas. This will not only change the regional education resource allocation, the basic contradiction of the supply of education resources shortage of regional expansion from suburban areas to suburban areas; moreover, due to the education resources in outer suburbs are relatively weak, agglomeration will further aggravate the migrant workers and their children in these areas to teach regional education resources shortage, is not conducive to the optimization and upgrading of education the resources of the outer zone (Smith,Malcolm,2009).

\subsection{Two child policy brings new difficulties}

The birth peak effect of household registration population and the adjustment of household registration policy will aggravate the contradiction between supply and demand of educational resources in the near future. Take Shanghai as an example, since 2000, Shanghai has gradually entered the fourth peak of population birth. Statistics show that Shanghai's permanent population of newborns increased from 81 thousand in 2001 to 166 thousand and 600 in 2007, nearly doubled. At the same time, Shanghai's registered population has continued to grow negatively since 1993. It is possible to adjust the current fertility policy around 2011, allowing couples with only one child to have two children. Once the new policy is implemented, many people will choose to give birth in the first time, which will lead to the accumulation effect of fertility. The increase in the number of school-age children and adolescents who receive compulsory education will pose a more severe challenge to the full implementation of compulsory education for migrant workers living with children in Shanghai and the demand for full-time public schools in the inflow areas.

\subsection{Household registration system and the restriction of the college entrance examination system}

Once the education channel for children of migrant workers has been established, it will have a certain impact on the compulsory education resources. Due to the restriction of the household registration system and the college entrance examination system, the children of migrant workers can not continue to receive equal rights in education after entering the junior middle school. In Shanghai, although the relevant government departments and the community have formed a consensus - will open the secondary vocational education to the children of migrant workers, but is limited to the pilot phase. We think, whether it is open or open education occupation education of senior high school, once the children of migrant workers after junior high school education channel is established, not only will increase the city high school education resources, also on the compulsory education resources especially the junior middle school education resources to form a 
larger impact (Steve, 2011).

\section{The Main Problems Faced by Migrant Workers' Children}

\subsection{Affected by its own and external factors}

Affected by their own and external factors, the education of migrant workers' children still faces many difficulties. The specific performance is as follows: first, there are some psychological barriers to the children of migrant workers who study in public schools. At present, the public schools to receive the children of migrant workers generally use the whole school admission and placement alone, BDEs and other forms of migrant workers relatively low social economic status determines their children vulnerable to age discrimination in public schools, such discrimination is not only an increase of peasant workers' children's psychological burden, but also not conducive to peer social fusion. Two, the new curriculum reform has increased the learning difficulties of migrant workers' children. Because the children of migrant workers contact education late, and the family education environment is poor, so the learning base is relatively poor. However, the difficulty of the new curriculum reform has increased, which has increased the learning difficulties of migrant workers' children. Three, the school conditions for children of migrant workers are uneven, and the quality of education in some schools needs to be improved. And the government's inspection and supervision generally only stay in the school safety and health, etc., for the quality of teaching and other substantive issues have not yet quantified standards.

\subsection{The policy of waiving tuition and fees has not yet been granted}

Tthe policy of waiving tuition and fees has not yet benefited all children of migrant workers, and the right to education of some low-income migrant workers' children is still difficult to guarantee. In Shanghai for example, has canceled the policy background Jiedufei of compulsory education in the country, Shanghai will face a dilemma: Cancel and ban school for children of migrant workers, will make part of the lower income and living conditions of the children do not conform to the contract without schooling of children of migrant workers; reduce or cancel the children of migrant workers into the public school how to solve the transient threshold, is part of the migrant workers children's education expenses and how to prevent more educated immigrants will become a big problem. If the above contradictions can not be properly and effectively solved, the new and illegal school children of migrant workers will continue to emerge because of the existence of the education market and profit opportunities. To sum up, migrant workers living area is relatively concentrated, resulting in regional education resource supply shortage and idle coexist; affected by the change of the future development of the floating population and related policies, there is greater uncertainty in the number of children of migrant workers in the stage of compulsory education is not perfect; the statistical system of education related functional departments is difficult to grasp the basic situation of children of migrant workers thus, increasing regional education resource allocation and the difficulty of planning; junior high school education channels and free compulsory education fees and policies to further increase the contradiction between supply and demand of resources is the core of financial pressure, and a condition for the threshold setting is forced to move, will obviously be a part of the children of migrant workers are deprived of education. To increase the difficulty of training schools for children of migrant workers. The education foundation of migrant children is weak, the process of social integration is slow, and the restriction of the household registration system of the college entrance examination also leads to the objective reality of the education difficulty. It should be said that the above problems will exist for a long period of time, and solving the education problem of migrant workers' children is also a long-term task. If not handled properly, it will not only affect the education process of migrant workers' children, but also affect the improvement of the compulsory education level of school-age population Whitney. 


\section{Solutions to the Education Problems of Migrant Workers' Children}

\subsection{Strengthen and improve the public service function of the government}

Strengthen and improve the public service function of the government, and bring the education resources of migrant workers' children into the urban social undertakings development plan. Firstly, according to the situation of population change in different regions, the allocation direction of educational resources is decided. The municipal government will increase the population of counties especially the children of migrant workers into the agglomeration district support, the education for children of migrant workers into the social development of city planning, will undertake more migrant workers children school construction is included in the planning of city infrastructure construction, the shortage of educational resources to increase the supply of regional public education resources, improve the ability of the county public schools accept the children of floating population. Second, the migrant workers residence planning guidance, timely adjustment of different areas of the school layout, so as to adapt with the new pattern of population. In order to disperse the density of the migrant children's living and schooling, the relevant government departments in the big city should plan and layout the residence of the migrant workers who have stable work (Fred, 2010).

\subsection{Funds for compulsory education of migrant workers' children}

Fund the compulsory education for the peasant workers' children, and set up the special fund for the students from economically difficult families. Firstly, we should construct the overall mode of the provision of compulsory education funds, and solve the problem of uneven educational resources between districts and counties. In view of characteristics of migrant workers housing is relatively concentrated, with high liquidity, in order to alleviate the contradiction of compulsory education resources in regional supply, construction funds supply mode of compulsory education for children of migrant workers in the inflow. According to the supply mode, the central government will return a sum of money from the central government to the three levels of governments in the cities, towns, districts and towns, as a special fund for the compulsory education funds for the children of migrant workers. Because the central tax return by the base method, so the essence of this model is: supply more economically developed, the per capita GDP is higher in the area, for the children of migrant workers to provide compulsory education resources also have more ability to bear the obligations and responsibilities of more. Second, the establishment of special funds to solve the problem of the pressure of migrant workers' children's educational expenses and the high cost of flowing schooling. The survey results show that most of the children who work in public schools and migrant workers' children schools can barely afford tuition and fees. In 2018, after the school of migrant workers' children was brought into the management of private education, the school running conditions and the teaching staff will be further strengthened, but at the same time, the cost of admission will also be improved accordingly. For this purpose, to reduce fees, reduce fees, establish a suitable economic situation of migrant workers reduce fees, school fees, meals, transportation fees, fees, and give a fee waiver and economic benefits, to help poor students in learning. Two should be based on city education surcharge and establish special funds through social sponsorship and other ways, through the establishment of grants, reducing costs, provide free textbooks way, help the families of the children of migrant workers (William, 2004).

\subsection{Construct preschool education, basic education, vocational education and adult education -- four teaching plans"}

Construct the characteristic education system of migrant workers' children of preschool education, basic education, vocational education, adult education, "four teaching and overall planning". It includes actively developing preschool education for migrant workers' children, improving compulsory education for migrant workers' children, and gradually opening up the education channels for children of migrant workers after junior high school. Since the reform of the household registration system in big cities has not yet broken the ice, coupled with the restriction of 
the education system of the college entrance examination, it is not feasible to fully open the educational channels for the children of migrant workers after junior high school at this stage. This paper suggests the adoption of "gradual release, conditional access, cost sharing, market operation". Gradually open, refers to the first open secondary vocational education, and then gradually transition to ordinary high school. Conditional access refers to the chain reaction that may be triggered by the development of certain access conditions to limit policy guidance. Cost sharing refers to the education after junior high school belongs to the non-compulsory education, so the source of education funds should be considered from various ways, and can adopt the "four aspects, each part of the way". Market operation refers to the cultivation and digestion of vocational schools with enterprise background, and enterprises can also entrust training methods to recruit students. The cost of education is shared by the enterprises, individuals and the three parties of the government, and the enterprises have the right to eliminate unqualified students in the recruitment process. At the same time, the government must make rules to strengthen the supervision of cost, price and education quality.

\section{Conclusion}

Due to historical, social and economic reasons, the problem of unequal educational opportunities still exists in our country at present stage, and the children of migrant workers are treated unfairly. The government in the allocation of funds to different education is one of the important reasons they encounter education predicament, so just through government efforts in education finance, will solve the problem of equal opportunity of education for children of migrant workers to provide a good material condition.

\section{Acknowledgement}

Project Name: The development of education mode of migrant workers' children under the background of educational informatization Item number: 14E026; Project Source: Heilongjiang philosophy and social science planning project; Project Name: A comparative study of Sino Russian higher education quality assurance system; Item number: GJE1214021; Project source: The project of Heilongjiang Education Science Planning Office

\section{References}

[1] Adeline, J., 2013. Migrant workers Suiqian children's compulsory education rights protection on Normal University.

[2] Baiansy, 2011. Migrant workers' children on Guangzhou University.

[3] Li, F.H., 2013.Compulsory education policy implementation of migrant workers' children on Zhengzhou University.

[4] Malcolm, S., 2009. Research on the effect of fiscal transfer payment of rural education expenditure: taking Zhejiang and Jiangxi as an example, education and economy.

[5] Pang, D.S., 2012. Compulsory education for children of migrant workers on Hunan Agricultural University 2012. 